Article

\title{
An Amino-Chain Modified $\beta$-cyclodextrin: A Supramolecular Ligand for Pd(OAc)2 Acceleration in Suzuki-Miyaura Coupling Reactions in Water
}

\author{
Vijay Vilas Shinde ${ }^{1}$, Daham Jeong ${ }^{2}$ and Seunho Jung ${ }^{1,2, *}$ \\ 1 Institute for Ubiquitous Information Technology and Applications (UBITA) \& Center for Biotechnology \\ Research in UBITA (CBRU), Konkuk University, Seoul 143-701, Korea; vijay.shinde040@gmail.com \\ 2 Department of Bioscience and Biotechnology, Microbial Carbohydrate Resource Bank (MCRB), \\ Konkuk University, Seoul 143-701, Korea; amir@konkuk.ac.kr \\ * Correspondence: shjung@konkuk.ac.kr; Tel.: +82-2-450-3520
}

Received: 31 December 2018; Accepted: 22 January 2019; Published: 23 January 2019

\begin{abstract}
A well-designed and synthesized water-soluble class of $\beta$-cyclodextrin supported palladium complex PdLn@Et- $\beta$-CD could efficiently validate high catalytic activity and act as a supramolecular platform for phosphine-free Suzuki-Miyaura cross-coupling reactions between arylboronic acid/arylboronic ester and aryl halides in water under mild conditions. The presented novel PdLn@Pr- $\beta$-CD complex catalyst was characterized by NMR, XRD, FT-IR, and DSC analysis. Furthermore, the role of the PdLn@Et- $\beta$-CD fragment in the reaction mechanism studied by molecular complexation was proposed based on FT-IR, 2D NMR (ROESY) spectroscopy, FE-SEM, and DSC spectroscopic analysis. The important benefits of this technique comprise simple phosphine-free preparation of the palladium catalyst, a wide range of functional-group tolerance, and easy recyclability; this method, furthermore, eschews hazardous reagents or solvents.
\end{abstract}

Keywords: ethylenediamine $\beta$-cyclodextrin; Suzuki-Miyaura; inclusion complex

\section{Introduction}

The Suzuki-Miyaura cross-coupling reaction is the most widely used protocol for the formation of carbon-carbon bonds and has become the predominant approach in the synthesis of biaryl [1-3], resulting in an extensive range of natural products and pharmaceuticals. In the Suzuki-Miyaura reaction, phosphine ligands are used to complex and activate the palladium species [4]. However, they are moisture and air sensitive, limiting the recyclability of the catalyst, and also lead to unwanted residues under aqueous reaction conditions, which place significant limitations on their synthetic applications $[5,6]$. Thus, the expansion of phosphine-free catalytic systems to overcome the above problems is considered to be one of the most demanding and challenging areas of organic synthesis [7]. With these issues in mind, many catalytic systems have been developed using various carriers to immobilize Pd catalysts, for example silica [8], Pd/C [9], magnetic nanoparticles [10-12], carbon nanotubes [13], nanomaterials [14-16], polymers [17,18], and cyclodextrins [19]. Among the various carriers, cyclodextrins (CD) have recently attracted abundant attention for Suzuki-Miyaura coupling reactions, given that phosphine free CD ligands support Pd catalytic systems [20-24].

Cyclodextrins are a well-known class of cyclic oligomers composed of a glucopyranoside unit, linked in $\alpha-1,4$ linkage. Their water solubility and ability to form an inclusion complex make them unique. This unique property endows it with different functions, such as drug delivery [25], selective recognition [26], and catalysis in water [27]. Recently different kinds of amino functionalized $\beta-C D$ ligands were synthesized and used for the different $C-C$ bond coupling reactions, such as Suzuki-Miyaura, Heck coupling, etc. [28,29]. Indeed, native $\beta-C D$ and its derivatives have 
shown outstanding performance in water mediated organic synthesis. However, the application of amino chain modified $\beta-C D$ derivatives as ligands in organometallic catalysis has not been fully explored, especially for $\mathrm{C}-\mathrm{C}$ bond coupling reactions in aqueous conditions [30-32]. Moreover, amino modified based ligand reports with complex multistep and reaction mechanism by molecular complexation were not studied. Hence, in this context we report on an ethylene- $\beta$-cyclodextrin supported palladium complex (PdLn@Et- $\beta-C D$ ) and how it catalyzed Suzuki-Miyaura coupling reactions in water. Additionally, the excellent catalytic activity and catalytic mechanism by molecular complexation were deliberate.

\section{Results and Discussion}

The construction procedure for aminoethylamino- $\beta$-cyclodextrin supported palladium complex (PdLn@Et- $\beta$-CD) involved four steps, as shown in Scheme 1. First, mono-6-(4-tosyl)-6-deoxy- $\beta$-CD (TsCD) was synthesized from commercially available $\beta-C D$ with 1 -(p-Toluenesulfonyl)imidazole in aqueous $\mathrm{NaOH}$, which was further reacted with ethylenediamine at $50{ }^{\circ} \mathrm{C}$ to give functionalized Ln@Et- $\beta$-CD. The resultant ligand was then blended with $\mathrm{Pd}(\mathrm{OAc})_{2}$ in anhydrous toluene for $15 \mathrm{~h}$, where the anticipated complex of PdLn@Et- $\beta$-CD was found as light yellow powder. Remarkably, the catalyst has shown outstanding solubility in water.

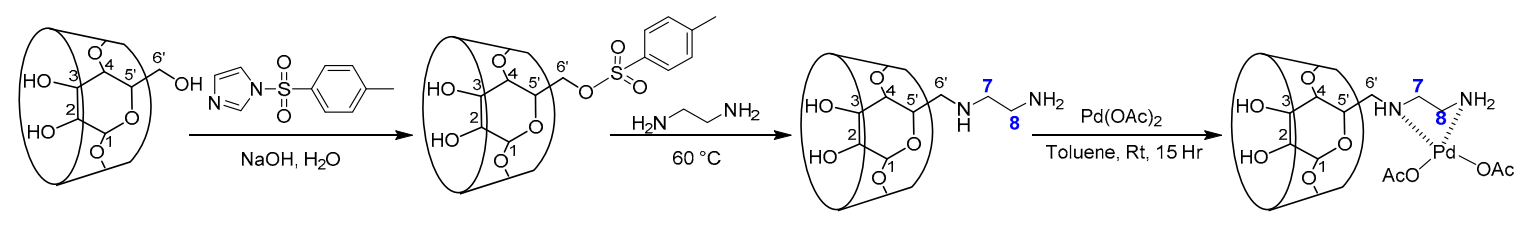

Scheme 1. Synthesis of the PdLn@Et- $\beta-C D$ catalyst.

To evidence the coordinative conformation of the Ln@Et- $\beta-C D$ ligand and PdLn@Et- $\beta-C D$ complex, ${ }^{1} \mathrm{H}$ NMR spectra were investigated, and the results are shown in Figure 1 . As demonstrated in Figure 1, the distinguishing peaks of Ln@Et- $\beta$-CD appeared at 2.7 to $2.9 \mathrm{ppm}$. Additionally, the 2:7 basic ratios of the $\mathrm{H} 7$ protons to the $\mathrm{H} 1$ protons confirmed that the ethylenediamine is monofunctionalized to the $\beta-C D$. This result proves the successful development of Ln@Et $\beta$-CD. Relating the spectrum of Ln@Et- $\beta-C D$ with that of PdLn@Et- $\beta-C D$, the peak of acetyl in PdLn@Et- $\beta$-CD was enormously noticeable and it afforded a clear signal that the PdLn@Et- $\beta-C D$ catalyst had been successfully synthesized. MALDI-TOF mass spectrometry was also used to demonstrate the clear synthesis of Ln@Et- $\beta$-CD (Figure S1; $m / z$ calculated for $\left[\mathrm{C}_{44} \mathrm{H}_{76} \mathrm{~N}_{2} \mathrm{O}_{34}\right] 1176.42$, found $1177.35[\mathrm{M}+\mathrm{H}]^{+}, 1199.34[\mathrm{M}$ $\left.+\mathrm{Na}]^{+}\right)$. The NMR and MALDI-TOF results indicated that the degree of substitution of Ln@Et- $\beta-\mathrm{CD}$ is 1 .
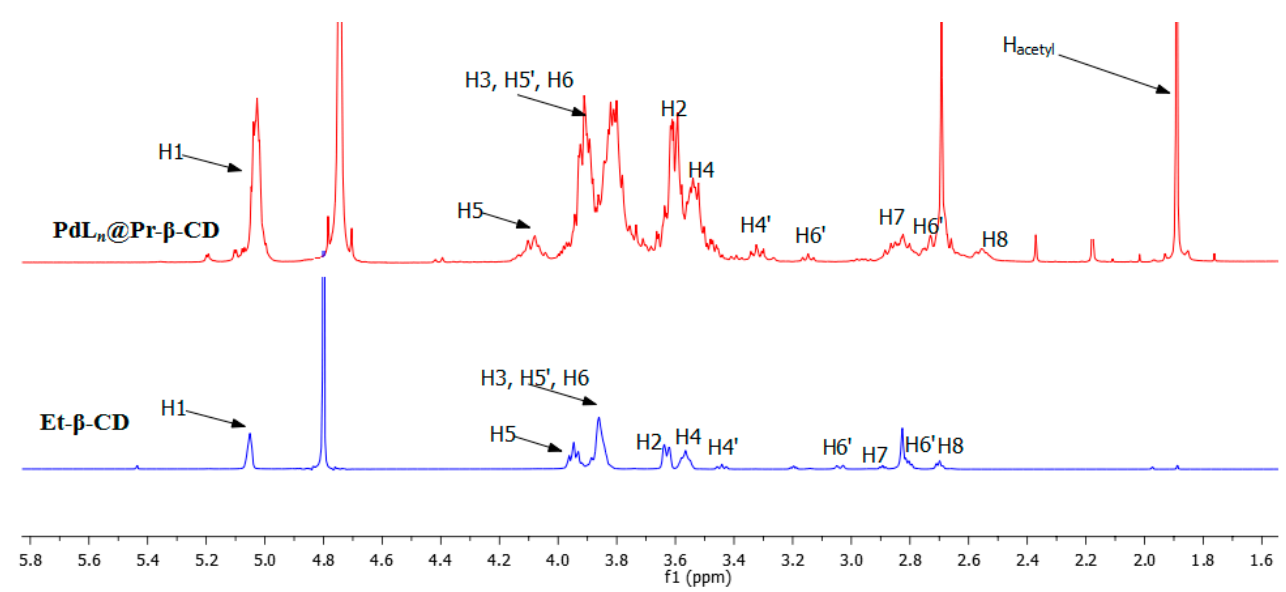

Figure 1. ${ }^{1} \mathrm{H}$ NMR spectra of Et- $\beta-C D$ and PdLn@Et- $\beta-C D$. 
In the FT-IR spectrum (Figure 2), characteristic bands of Et- $\beta-C D$ and PdLn@Et- $\beta-C D$ were observed. The free Et $\beta$-CD ligand exhibited bands at $3336 \mathrm{~cm}^{-1}$ corresponding to stretching frequencies of hydroxyl groups. The band at $2928 \mathrm{~cm}^{-1}$ corresponded to aliphatic $\mathrm{C}-\mathrm{H}$ stretching, and the band at $1107 \mathrm{~cm}^{-1}$ corresponded to the $\mathrm{C}-\mathrm{N}$ stretching frequency of $\mathrm{Et}-\beta-\mathrm{CD}$. After complex formation of Et- $\beta-C D$ with $\operatorname{Pd}(\mathrm{OAc})_{2}$, each of the IR frequencies were shifted to $2948 \mathrm{~cm}^{-1}, 3410 \mathrm{~cm}^{-1}$, and $1182 \mathrm{~cm}^{-1}$, which corresponded to $\mathrm{C}-\mathrm{H}, \mathrm{O}-\mathrm{H}$, and $\mathrm{C}-\mathrm{N}$ stretching frequencies, respectively. Furthermore, the peak around $1717 \mathrm{~cm}^{-1}$ indicated the $\mathrm{C}=\mathrm{O}$ stretching vibrations, which corresponded to the carbonyl group of palladium acetate. These changes provided additional supporting evidence for the formation of PdLn@Et- $\beta-C D$ complex.

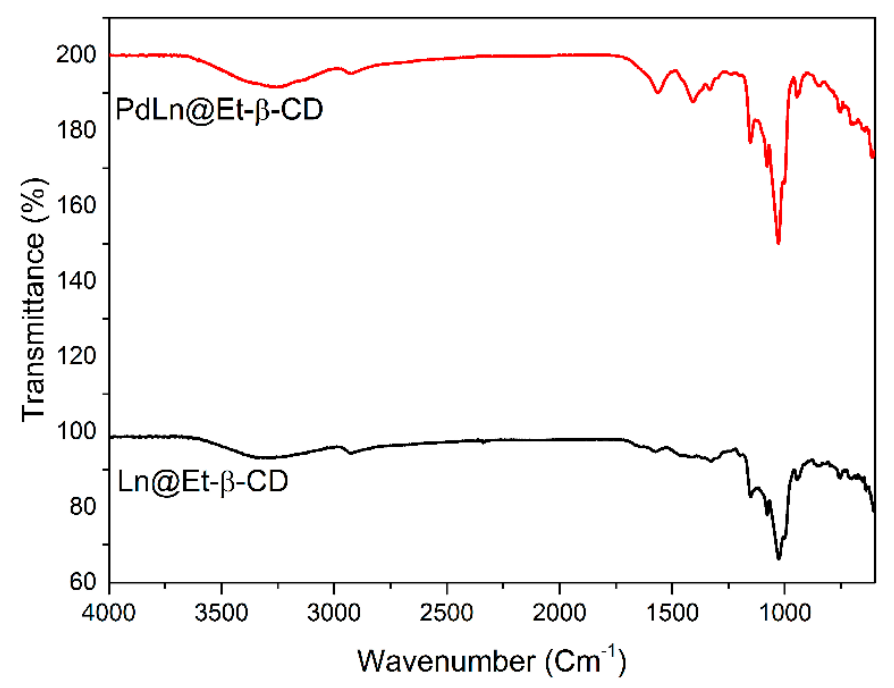

Figure 2. FT-IR spectra of Et- $\beta-C D$ and PdLn@Et- $\beta-C D$.

The patterns of X-ray diffraction (XRD) of Et- $\beta-C D$ and PdLn@Et- $\beta-C D$ are presented in Figure 3. These results indicated that Et- $\beta-C D$ (black curve) and PdLn@Et- $\beta-C D$ (red curve) are both amorphous and display a robust and distinctive diffraction peak at $2 \theta$ of $15-30^{\circ}$. Furthermore, the new peaks in the XRD pattern of PdLn@Et- $\beta$-CD at $2 \theta$ of $39.5^{\circ}$ and $47.2^{\circ}$, matching the 110 and 200 crystalline planes of Pd2, specified the presence of Pd in PdLn@Et- $\beta$-CD. As a result, the XRD patterns proved that the catalyst had been synthesized without damaging the crystal structure of the Et- $\beta-C D$ ligand, and Pd was present in the PdLn@Et- $\beta$-CD catalyst.

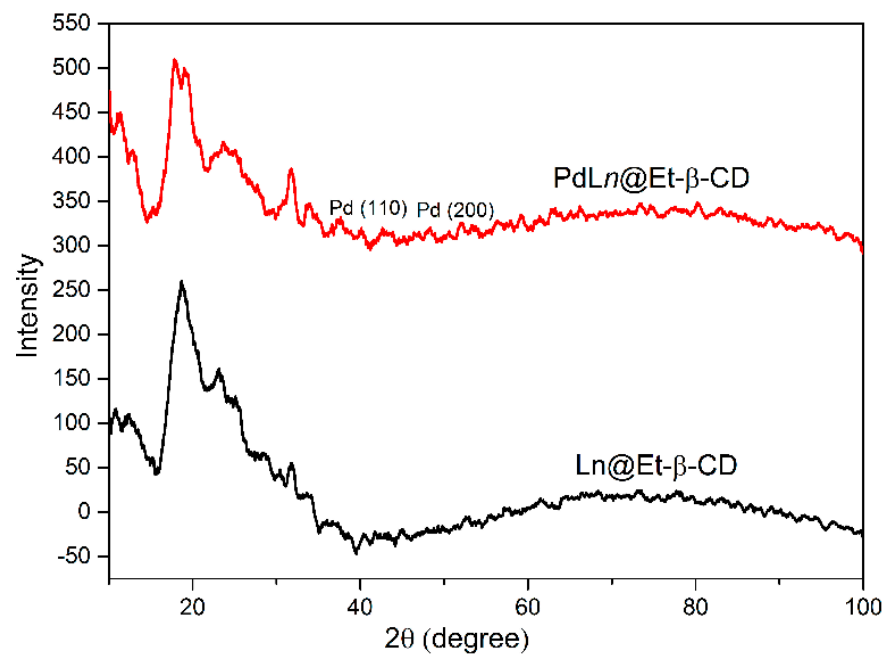

Figure 3. XRD patterns of Et- $\beta-C D$ and PdLn@Et- $\beta-C D$. 
To evaluate the catalytic performance of PdLn@Et- $\beta$-CD catalysts, Suzuki-Miyaura coupling reactions were carried out as model reactions. Initially, 1-bromo-4-nitrobenzene and (3-methoxyphenyl)boronic acid were selected as the model substrates to investigate the optimal reaction conditions, and the results are depicted in Table 1 . A moderate $71 \%$ yield of the desired product was obtained when the reaction was carried out with $1 \mathrm{~mol} \%$ of PdLn@Et- $\beta-\mathrm{CD}$ and $\mathrm{Na}_{2} \mathrm{CO}_{3}$ base in water at $60{ }^{\circ} \mathrm{C}$ for $2 \mathrm{~h}$ (Table 1, entry 1), which indicated that the PdLn@Et- $\beta$-CD catalyst and base $\mathrm{Na}_{2} \mathrm{CO}_{3}$ played a significant role in the reaction. Furthermore, different bases were also tested, and we found $\mathrm{K}_{2} \mathrm{CO}_{3}$ to be the optimal base when compared with other bases like $\mathrm{Cs}_{2} \mathrm{CO}_{3}, \mathrm{~K}_{3} \mathrm{PO}_{4}$, and $\mathrm{NaHCO}_{3}$ (Table 1, entries 2-5). In the absence of a base, no significant product development was detected even after $14 \mathrm{~h}$ of reaction time (Table 1 , entry 6). Later on, the catalyst loading was optimized by increasing the quantity of catalyst loading to $1.5,2$ and $2.5 \mathrm{~mol} \%$. Remarkably, $2 \mathrm{~mol} \%$ of catalyst was found to give the maximum yield in less time (Table 1, entry 8). Further increasing the quantity of the PdLn@Et- $\beta-C D$ catalyst ( $3 \mathrm{~mol} \%$ ) neither improved the yield nor reduced the conversion time (Table 1, entry 10 ). After finding the optimum catalyst and base loading condition, the effects of temperature were also investigated. When the reaction was carried out below the $60^{\circ} \mathrm{C}$, the yield of the desired product notably decreased. Furthermore, a temperature increase to $70-100{ }^{\circ} \mathrm{C}$ neither increased the yield nor reduced the conversion time. In order to clarify the role of $\beta$-cyclodextrin $(\beta-C D)$ in aqueous reactions, a controlled reaction was carried out using $\beta-\mathrm{CD}(5 \mathrm{~mol} \%)$ and $\mathrm{Pd}(\mathrm{OAc})_{2}(2.5 \mathrm{~mol} \%)$. Trace product formation was observed using native $\beta$-cyclodextrin as the catalyst even after $15 \mathrm{~h}$ of reaction time (Table 1, entry 16), which strongly indicated the importance of the ligand group in $\mathrm{CD}$ to stabilize $\mathrm{Pd}(\mathrm{OAc})_{2}$ in this reaction.

Table 1. Optimization of the reaction conditions ${ }^{a}$.

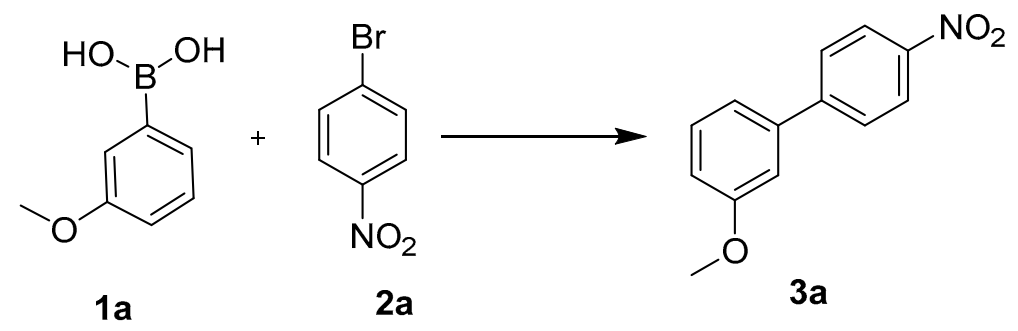

\begin{tabular}{|c|c|c|c|c|c|}
\hline Entry & Catalyst (mol\%) & Base & Temperature $\left({ }^{\circ} \mathrm{C}\right)$ & Time (h) & Yield (\%) ${ }^{b}$ \\
\hline 1 & PdLn@Et- $\beta-C D(1)$ & $\mathrm{Na}_{2} \mathrm{CO}_{3}$ & 60 & 2 & 71 \\
\hline 2 & PdLn@Et- $\beta-C D(1)$ & $\mathrm{Cs}_{2} \mathrm{CO}_{3}$ & 60 & 2 & 76 \\
\hline 3 & PdLn@Et- $\beta$-CD (1) & $\mathrm{K}_{3} \mathrm{PO}_{4}$ & 60 & 3 & 68 \\
\hline 4 & PdLn@Et- $\beta$-CD (1) & $\mathrm{NaHCO}_{3}$ & 60 & 3 & 59 \\
\hline 5 & PdLn@Et- $\beta-C D(1)$ & $\mathrm{K}_{2} \mathrm{CO}_{3}$ & 60 & 1 & 90 \\
\hline 6 & PdLn@Et- $\beta-C D(1)$ & - & 60 & 14 & - \\
\hline 7 & PdLn@Et- $\beta-C D(1.5)$ & $\mathrm{K}_{2} \mathrm{CO}_{3}$ & 60 & 1 & 90 \\
\hline 8 & PdLn@Et- $\beta-C D(2)$ & $\mathrm{K}_{2} \mathrm{CO}_{3}$ & 60 & 1 & 94 \\
\hline 9 & PdLn@Et- $\beta-C D(2.5)$ & $\mathrm{K}_{2} \mathrm{CO}_{3}$ & 60 & 1 & 94 \\
\hline 10 & PdLn@Et- $\beta-C D(3)$ & $\mathrm{K}_{2} \mathrm{CO}_{3}$ & 60 & 1 & 93 \\
\hline 11 & PdLn@Et- $\beta-C D(2)$ & $\mathrm{K}_{2} \mathrm{CO}_{3}$ & 40 & 6 & 72 \\
\hline 12 & PdLn@Et- $\beta$-CD (2) & $\mathrm{K}_{2} \mathrm{CO}_{3}$ & 50 & 4 & 84 \\
\hline 13 & PdLn@Et- $\beta$-CD (2) & $\mathrm{K}_{2} \mathrm{CO}_{3}$ & 70 & 1 & 94 \\
\hline 14 & PdLn@Et- $\beta-C D(2)$ & $\mathrm{K}_{2} \mathrm{CO}_{3}$ & 90 & 1 & 94 \\
\hline 15 & PdLn@Et- $\beta-C D(2)$ & $\mathrm{K}_{2} \mathrm{CO}_{3}$ & 100 & 1 & 94 \\
\hline 16 & $\begin{array}{c}\beta-\mathrm{CD}(5) / \mathrm{Pd}(\mathrm{OAc})_{2} \\
(2.5)\end{array}$ & $\mathrm{K}_{2} \mathrm{CO}_{3}$ & 60 & 15 & 11 \\
\hline
\end{tabular}

a Reactants: 1-bromo-4-nitrobenzene (2a, $1 \mathrm{mmol})$, (3-methoxyphenyl)boronic acid (1a, $1.2 \mathrm{mmol}$ ), catalyst PdLn@Et- $\beta-C D$, and water $3 \mathrm{~mL} .{ }^{\mathrm{b}}$ Isolated yield.

Having determined the best conditions, we continued to examine the substrate scope of the catalytic system. The obtained results are outline in Table 2. Diverse aryl halides were used for coupling reactions with different arylboronic acids to give the corresponding biaryl products in good to excellent 
yields. All things considered, the catalyst showed good catalytic activity, leading to outstanding yields in the Suzuki-Miyaura coupling reactions. General aryl halides, such as bromobenzene and iodobenzene, had a high reactivity with boronic acid, and the reactions were rapidly completed in $1 \mathrm{~h}$, as indicated in entries 1 and 2 of Table 2. The substrates with electron donating functionality, such as $-\mathrm{CH}_{3}$ and -OMe, afforded the coupling products in good yields, but required longer reaction times (Table 2, entries 7, 11-13, 18). In contrast, aryl halides containing electon withdrawing groups, such as $-\mathrm{NO}_{2},-\mathrm{CHO}$, and $-\mathrm{OH}$, gave high yields in shorter reaction times (Table 2, entries 1-6, 14-16). However, only a moderate yields were obtained when aryl chlorides were used as the substrate (Table 2, entries 19). Additionally, the optimized reaction conditions were operative for the Suzuki-Miyaura coupling of heteroaryl bromides with phenylboronic acids and produced products in acceptable yields (Table 2, entries 17).

Table 2. Suzuki-coupling between aryl halides and arylboronic acids, catalyzed by PdLn@Et- $\beta-C D$ a

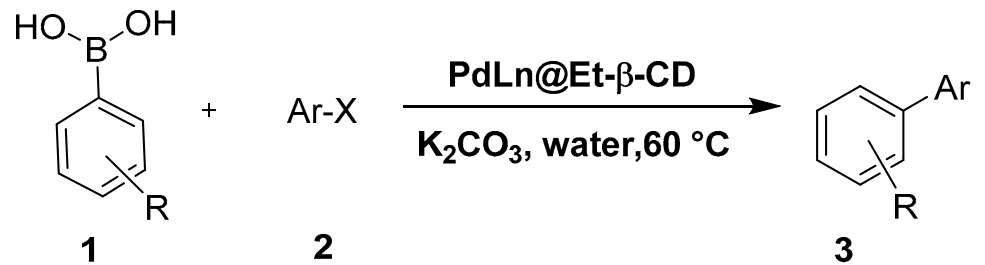

\begin{tabular}{|c|c|c|c|c|c|}
\hline Entry & $\mathbf{R}$ & Ar & $X$ & Compound & Yield (\%) ${ }^{b}$ \\
\hline 1 & $4-\mathrm{CH}_{3} \mathrm{O}-\mathrm{C}_{6} \mathrm{H}_{4}$ & $4-\mathrm{NO}_{2}$ & $\mathrm{Br}$ & $3 a$ & 94 \\
\hline 2 & $\mathrm{Ph}$ & $4-\mathrm{NO}_{2}$ & $\mathrm{Br}$ & $3 b$ & 98 \\
\hline 4 & 2,4 -difluoro- $\mathrm{C}_{6} \mathrm{H}_{3}$ & $4-\mathrm{NO}_{2}$ & $\mathrm{Br}$ & $3 d$ & 90 \\
\hline 5 & 2,4 -difluoro- $\mathrm{C}_{6} \mathrm{H}_{3}$ & $4-\mathrm{OH}$ & $\mathrm{Br}$ & $3 e$ & 91 \\
\hline 8 & $\mathrm{Ph}$ & $\mathrm{Ph}$ & $\mathrm{I}$ & $3 \mathrm{~h}$ & 98 \\
\hline 9 & 1-naphthalene & 5-indole & $\mathrm{Br}$ & $3 \mathrm{i}$ & 90 \\
\hline 10 & $\mathrm{Ph}$ & 2-phenylpropan-2-ol & $\mathrm{Br}$ & $3 \mathrm{j}$ & 93 \\
\hline 11 & $\mathrm{Ph}$ & 4-OMe & $\mathrm{Br}$ & $3 \mathrm{k}$ & 96 \\
\hline 12 & $\mathrm{Ph}$ & 2-Me & $\mathrm{I}$ & 31 & 97 \\
\hline 16 & $2,4-(\mathrm{CF} 3)_{2}-\mathrm{C}_{6} \mathrm{H}_{3}$ & $4-\mathrm{OH}$ & $\mathrm{Br}$ & $3 p$ & 91 \\
\hline 17 & $\mathrm{Ph}$ & 2-Py & I & $3 q$ & 92 \\
\hline 18 & $4-\mathrm{Cl}-\mathrm{C}_{6} \mathrm{H}_{4}$ & 4-OMe & $\mathrm{Br}$ & $3 r$ & 95 \\
\hline 19 & $\mathrm{Ph}$ & $4-\mathrm{NO}_{2}$ & $\mathrm{Cl}$ & $3 s$ & 54 \\
\hline
\end{tabular}

${ }^{a}$ The reaction conditions: arylboronic acid $(1,1.2 \mathrm{mmol})$, aryl halides $(2,1 \mathrm{mmol})$, PdLn@Et $\beta$-CD catalyst $(2 \mathrm{~mol} \%)$, and $\mathrm{K}_{2} \mathrm{CO}_{3}(1.5 \mathrm{mmol})$ in water $(4 \mathrm{~mL})$ under air. ${ }^{\mathrm{b}}$ Isolated yield. ${ }^{\mathrm{c}}$ Reactions were carried out using boronic ester.

Consequently, in order to progress the applications of PdLn@Et- $\beta-C D$, recycling of the catalyst was carried out. The overall procedure for recycling the catalytic system is shown in Figure 4.

Moreover, the reaction was conducted with the optimal reaction conditions: 1-bromo-4nitrobenzene (1a, $1 \mathrm{mmol}$ ), (3-methoxyphenyl)boronic acid (2a, $1.2 \mathrm{mmol})$, catalyst PdLn@Et- $\beta$-CD $(2 \mathrm{~mol} \%) \mathrm{K}_{2} \mathrm{CO}_{3}(1.5 \mathrm{mmol})$, and water $4 \mathrm{~mL} 60^{\circ} \mathrm{C}$. After completing each cycle, $3 \times 6 \mathrm{~mL}$ of ethyl acetate was added to isolate the organic layer, and the aqueous layer was then used in the next run without altering the reaction conditions. The recycling results are shown in Figure 5. In the first cycle, the yield was $94 \%$, and the PdLn@Et- $\beta$-CD catalyst still showed high catalytic activity, giving a yield of $89 \%$ even after seven cycles. 


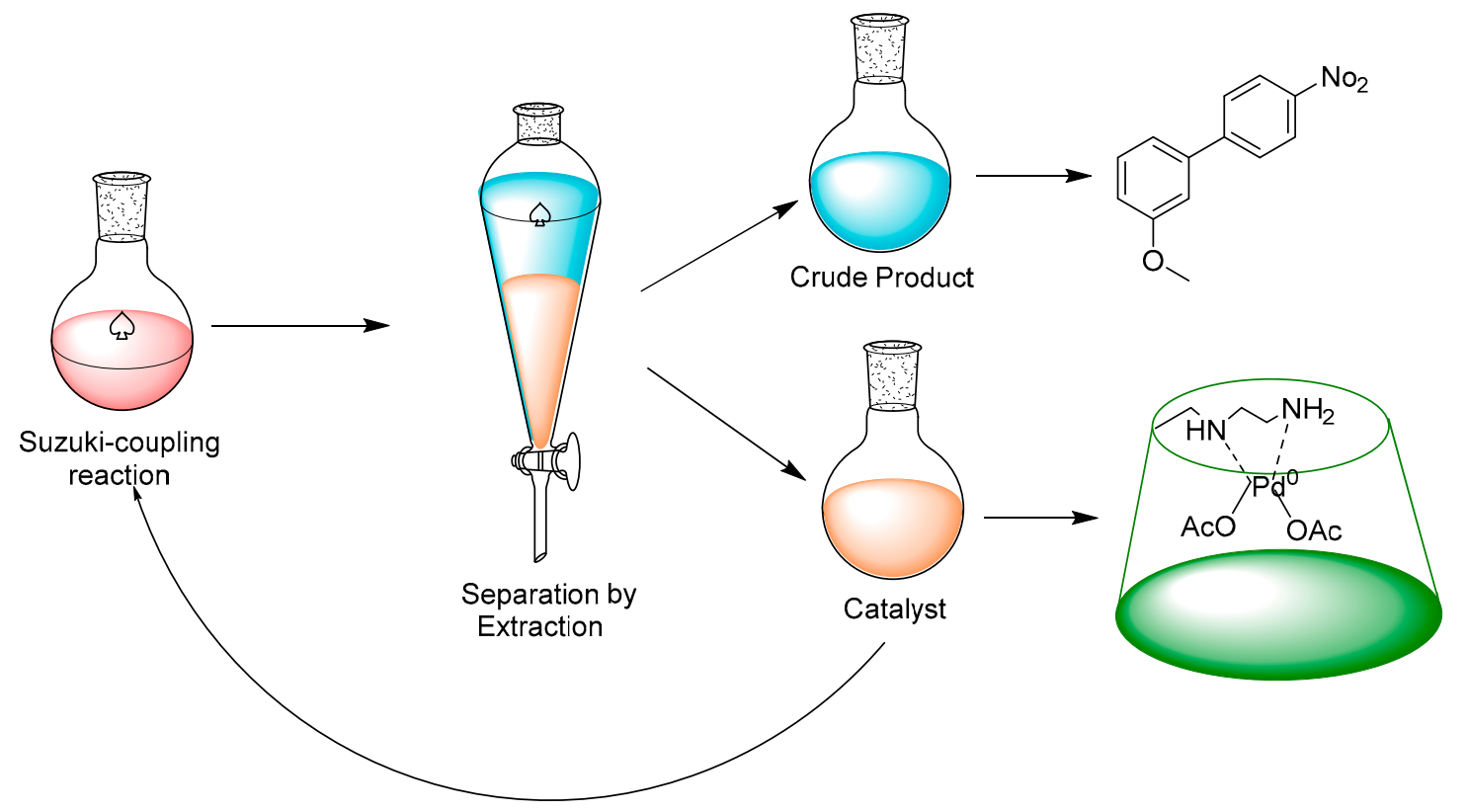

Figure 4. Recycling procedure for PdLn@Et- $\beta-C D$.

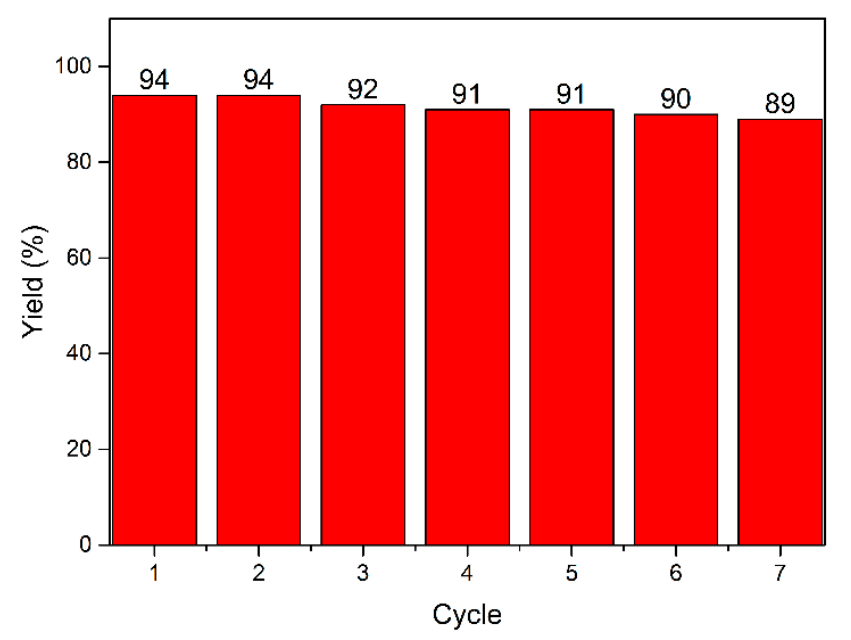

Figure 5. Recycling of PdLn@Et- $\beta-C D$.

To further prove the role of the PdLn@Et- $\beta-C D$ catalyst in the reactions, the inclusion complexation of the reactants and PdLn@Et- $\beta-C D$ was investigated. Two-dimensional (2D) NMR spectroscopy gave the most powerful evidence for the formation of inclusion complexes [33]. The protons in a molecule, which are situated within $0.4 \mathrm{~nm}$ in space, may produce a rotating-frame in NOE spectroscopy (ROESY). As shown in Figure 6, the hydrogens on the 1-bromo-4-nitrobenzene (BN) displayed clear NOE interactions with the $\mathrm{H} 3$ and $\mathrm{H} 5$ protons of PdLn@Et- $\beta-\mathrm{CD}$. Additionally, the ROESY experiment explained the inclusion mode of the PdLn@Et- $\beta-\mathrm{CD} / \mathrm{BN}$ complex. The spectrum displayed typical NOE relationships between the aromatic protons of $\mathrm{BN}$ at 7.38 and $6.83 \mathrm{ppm}$, and the inside the cavity, $\mathrm{H} 3$ and $\mathrm{H} 5$ protons of PdLn@Et- $\beta-\mathrm{CD}$ were detected at 3.88 and 3.94 ppm, respectively (see the enlarged view in Figure 5). Moreover, no NOE connection between the H1 proton of PdLn@Et- $\beta-C D$ and BN was detected, as it is well-known that the $\mathrm{H} 1$ proton exists on the external part of the PdLn@Et- $\beta-C D$ cavity. Hence, the role of the $\beta$-CD-fragment of PdLn@Et- $\beta$-CD was confirmed: it improved the water-solubility of the catalyst as well as housed the substrate by a molecular recognition method. 


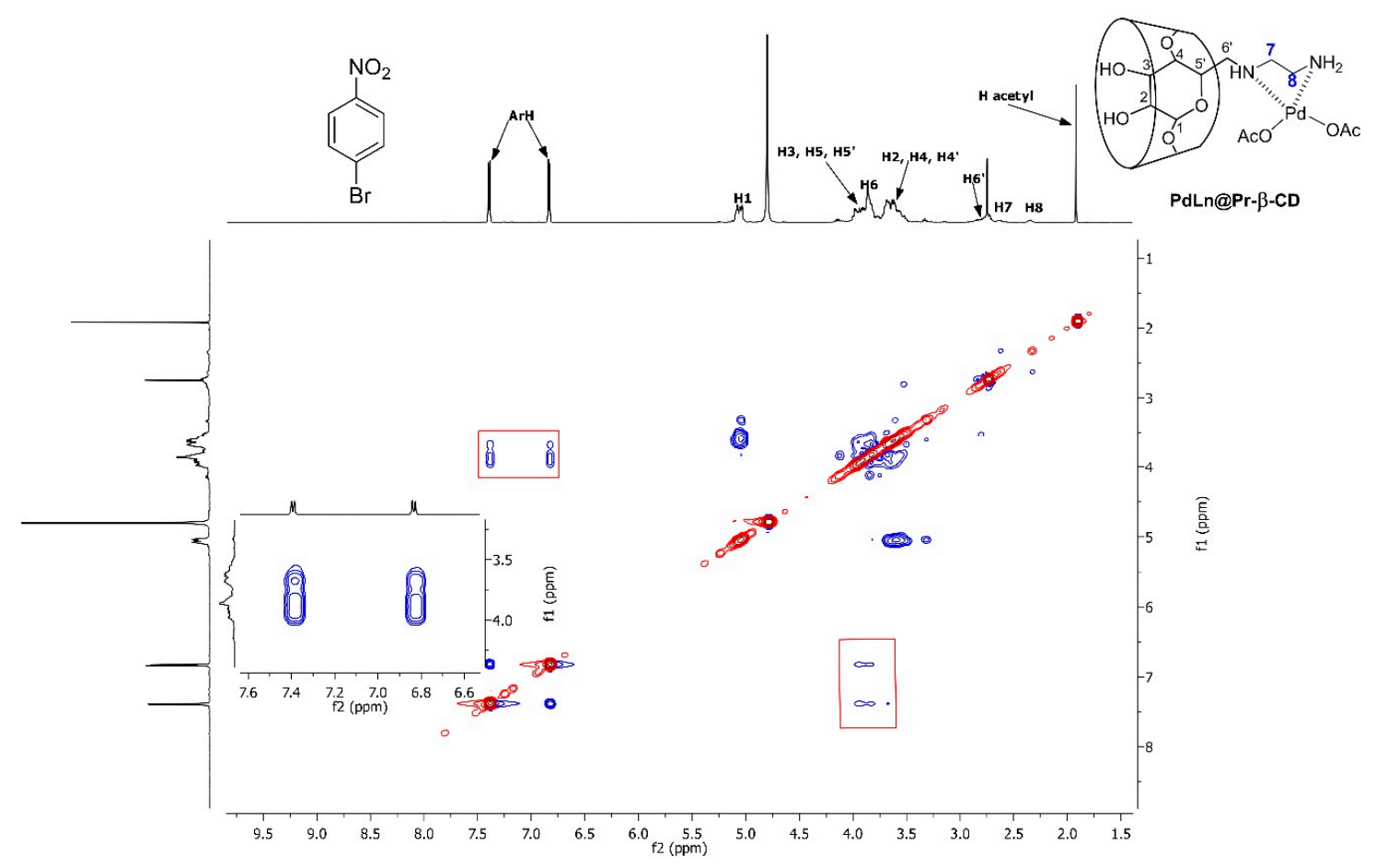

Figure 6. 2D ROESY NMR spectrum (600 MHz) of the PdLn@Et- $\beta-C D$ complex with BN. The solution contained deuterium oxide (D, 99.9\%), BN (10 mM), and PdLn@Et- $\beta-C D(10 \mathrm{mM})$. Mixing time: $400 \mathrm{~ms}$.

Furthermore, using FT-IR spectroscopy [34], we studied the vibrational changes upon complexation. The FT-IR spectra of PdLn@Et- $\beta-C D, B N$, the BN/PdLn@Et- $\beta-C D$ physical mixture, and the BN/PdLn@Et- $\beta$-CD inclusion complex are shown in Figure 7. The PdLn@Et- $\beta$-CD spectrum contained the characteristic absorption band for the spectrum with $\mathrm{O}-\mathrm{H}$ stretching at $3410 \mathrm{~cm}^{-1}$, sp3 C-H stretching around $2948 \mathrm{~cm}^{-1}$, and C-O stretching around $1030 \mathrm{~cm}^{-1}$. The N-H stretching vibrations were observed at $1631 \mathrm{~cm}^{-1}$ and $1576 \mathrm{~cm}^{-1}$. The red line spectrum of BN showed the distinctive absorption band of the $\mathrm{N}=\mathrm{O}$ of nitro at $1520 \mathrm{~cm}^{-1}$, and the individual 1-bromo-4-nitrobenzene at $3074 \mathrm{~cm}^{-1}$. The two peaks detected at 1540 and $1481 \mathrm{~cm}^{-1}$ were allotted to the aromatic ring of BN. The FT-IR spectrum of the physical mixture included absorption peaks with reduced intensities at locations matching to that of the natural $\mathrm{BN}$, demonstrating that the simple mixture of $\mathrm{BN}$ and PdLn@Et- $\beta$-CD dids not change the physical properties of BN. However, the distinguishing absorption peaks at 3074 and $1520 \mathrm{~cm}^{-1}$ vanished in the FT-IR spectrum of the BN/PdLn@Et- $\beta-C D$ inclusion complex, demonstrating that the BN environment was different. This suggests that the existence of intense molecular connections in the complex can be mostly attributed to the hydrophobic interactions inside of the inclusion complex.

Scanning electron microscopy (SEM) is an exceedingly well-known technique for analyzing the surface texture and particle size changes in inclusion complexation [35]. Figure 8 displays the SEM images of PdLn@Et- $\beta-C D, B N$, a physical mixture of PdLn@Et- $\beta-C D / B N$, and the PdLn@Et- $\beta-C D / B N$ inclusion complex. PdLn@Et- $\beta$-CD was spherical and amorphous, where BN occured as needle-like crystals. In the physical mixture of the two powders, the representative crystals of $\mathrm{BN}$ and the amorphous spheres of PdLn@Et- $\beta$-CD were both detected. In contrast, the inclusion complex contained unevenly shaped particles in which the original morphologies of both compounds were obscured, and collections of amorphous fragments of irregular sizes were detected. Thus, the data gained from SEM analysis propose that the inclusion complexation method between BN and PdLn@Et- $\beta$-CD occured in a solution state. 


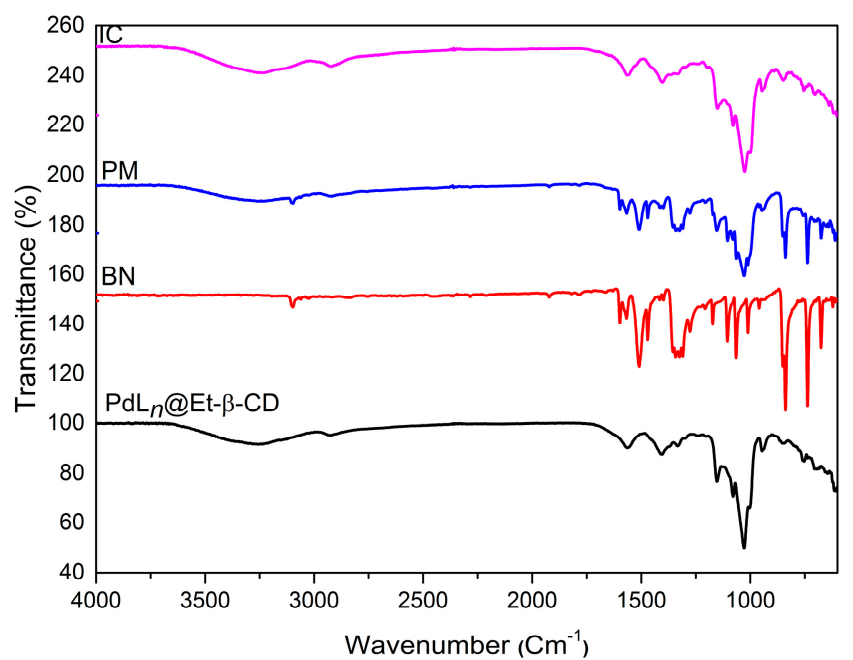

Figure 7. FT-IR spectra of PdLn@Et- $\beta-C D, B N$, a physical mixture of BN/PdLn@Et- $\beta-C D(P M)$, and the BN/PdLn@Et- $\beta$-CD complex (IC).
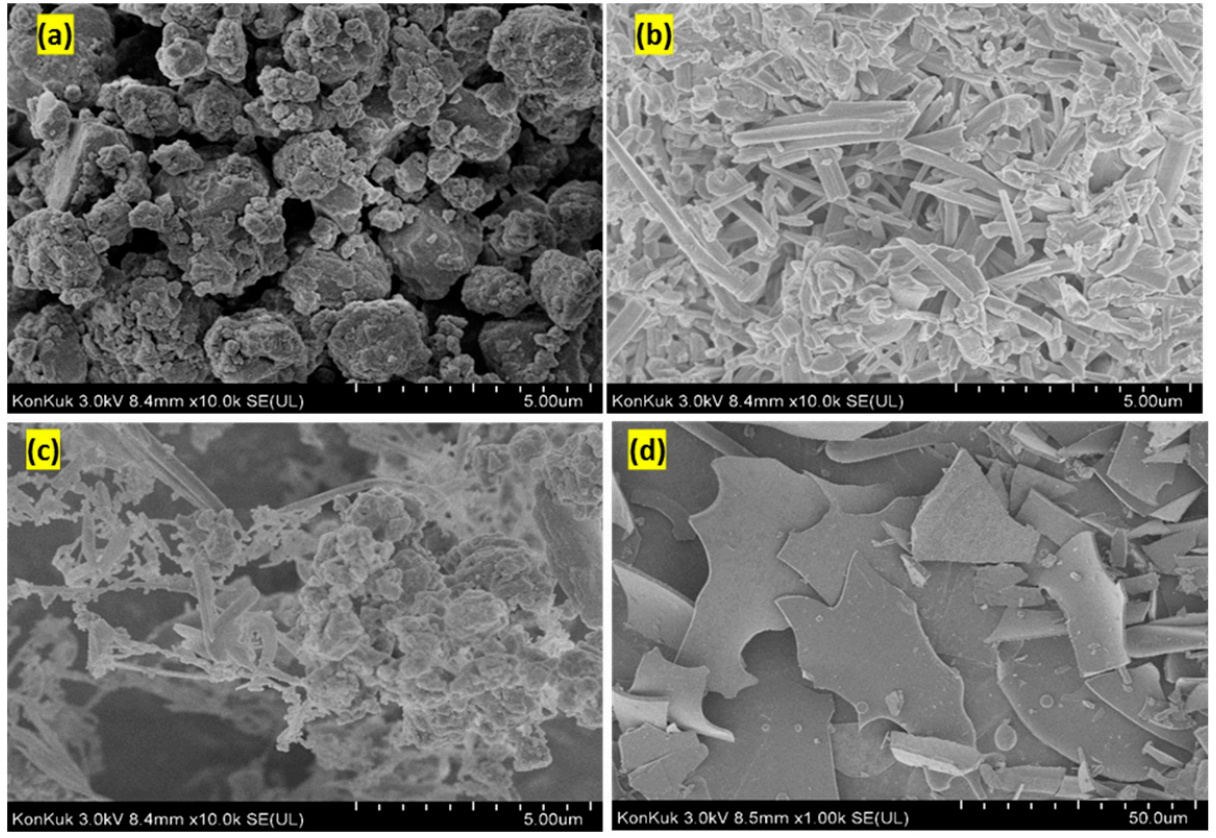

Figure 8. Scanning electron micrographs of (a) PdLn@Et- $\beta-C D$, (b) 1-bromo-4-nitrobenzene (BN), (c) their physical mixture, and (d) inclusion complex.

Differential scanning calorimetry (DSC) analysis characterizes the interactions between the host and guest molecules in a solid state [36]. Figure 9 shows the DSC thermogram of PdLn@Et- $\beta-C D, B N$, a physical mixture of BN/PdLn@Et- $\beta-C D$, and the BN/PdLn@Et- $\beta-C D$ inclusion complex. BN had a sharp endothermic peak at $125^{\circ} \mathrm{C}$, which was its melting point. The DSC curve of PdLn@Et- $\beta-C D$ contained an endothermic peak at around $323^{\circ} \mathrm{C}$, and for the physical mixture of BN/PdLn@Et- $\beta-C D$, the endothermic peak of $\mathrm{BN}$ was observed at $122.5^{\circ} \mathrm{C}$. This small alteration could be attributed to solid-solid interaction. However, in the DSC curve of the BN/PdLn@Et- $\beta-C D$ inclusion complex, the endothermic peak of free $\mathrm{BN}$ had clearly disappeared. These results suggest that the formation of complexes containing BN and PdLn@Et- $\beta-C D$ induced a change in the crystal state of BN. 


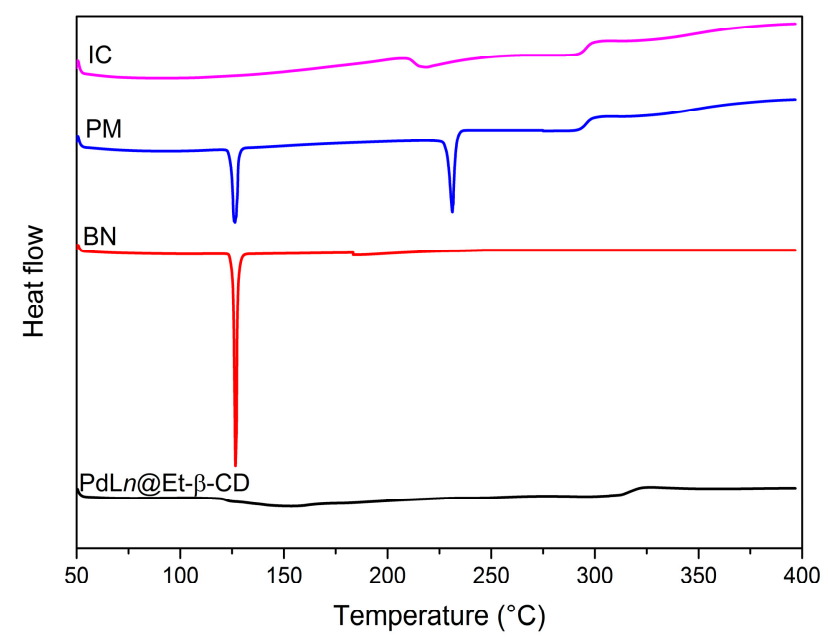

Figure 9. DSC of PdLn@Et- $\beta-C D, 1$-bromo-4-nitrobenzene (BN), their physical mixture (PM), and inclusion complex (IC).

Plausible mechanisms for the synthesis of Suzuki-Miyaura cross-coupling reactions involved three sequational steps, such as oxidative addition, transmetalation, and reductive elimination [37]. At first, PdLn@Et- $\beta$-CD was initiated to $\operatorname{Pd}(0)$; then, oxidative addition of aryl halides (2a) with active PdLn@Et- $\beta$-CD led to the generation of intermediate $\mathbf{A}$. Next, the insertion of the phenyl from phenylboronic acid (1a) through the transmetallation reaction provided $\mathbf{B}$, which underwent reductive elimination, and finally, the desired product was released from the cavity (see Figure 10).
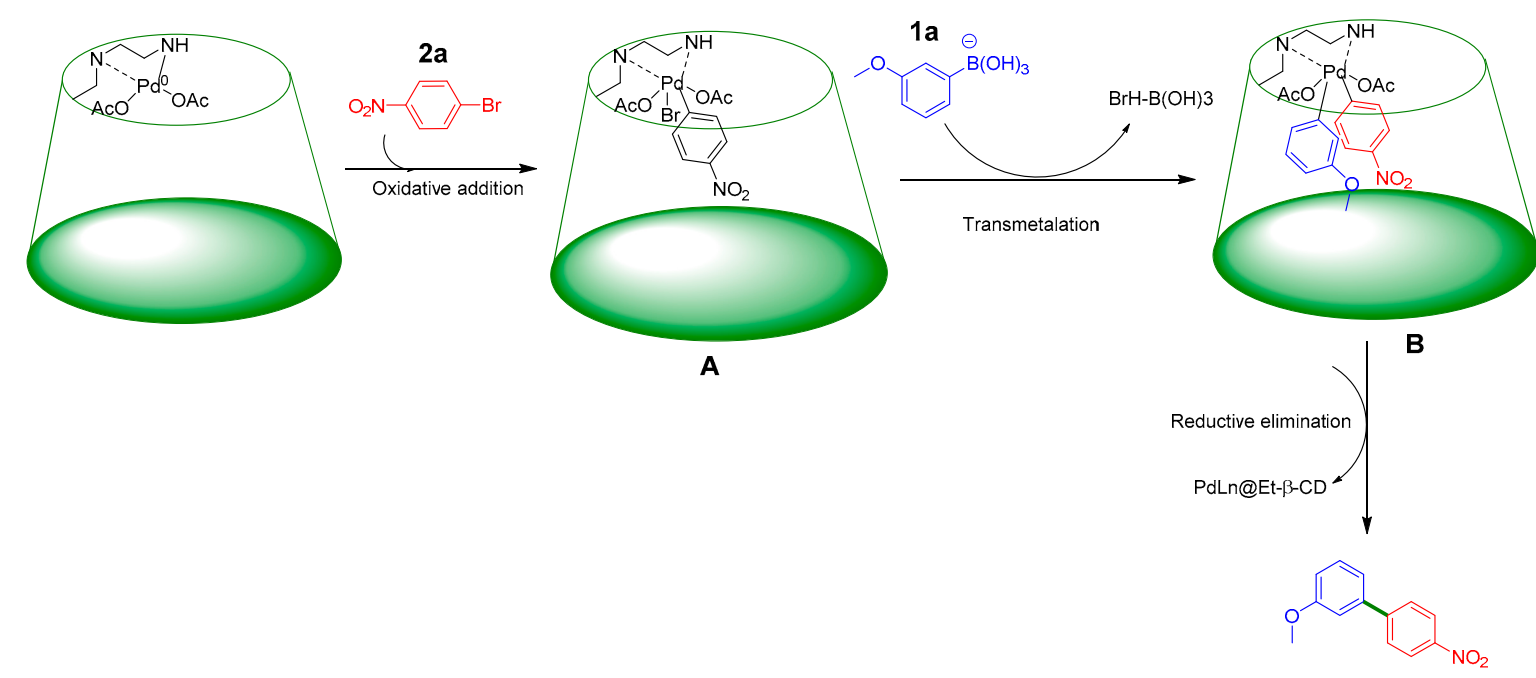

Figure 10. Possible mechanism of Suzuki-Miyaura cross-coupling reaction using PdLn@Et- $\beta$-CD. aryl halides (2a), oxdaive addition intermediate (A), phenyl from phenylboronic acid (1a), transmetallation intermediate $\mathbf{( B )}$.

\section{Experimental Materials}

All chemicals were purchased from commercial suppliers (Aldrich or Alfa Aesar) and were used without further purification. A Direct-Q Millipore water purification system was used to purify the water. Thin-layer chromatography (TLC) was performed using a Merck silica gel 60 F254 plate. NMR spectra were recorded on a Bruker Avance 500 spectrometer (Bruker, Karlsruhe, Germany) in $\mathrm{D}_{2} \mathrm{O}$ or $\mathrm{CDCl}_{3}$. 


\subsection{Characterization}

Fourier-transform infrared (FTIR) spectra were determined with a Nicolet 6700 (Thermo Scientific, Waltham, MA, USA) instrument using the attenuated total reflection (ATR) technique. X-ray diffraction (XRD) measurements were obtained using a X-ray diffractometer (Bruker D8 DISCOVER, Karlsruhe, Germany). Differential scanning calorimetry (DSC) were performed with a Discovery DSC (TA Instrument, New Castle, DE, USA) instrument. The samples were prepared in aluminum pans and scanned from 50 to $400{ }^{\circ} \mathrm{C}$ at a rate of $10^{\circ} \mathrm{C} / \mathrm{min}$ under a flow of nitrogen at $100 \mathrm{~mL} / \mathrm{min}$. The surfaces morphologies of the materials were examined using a field emission scanning electron microscope with a Hitachi S-4700 (Hitachi High-Technologies Corporation, Tokyo, Japan) instrument. For the NMR spectroscopic analysis, a Bruker Avance 500/600 spectrometer (Bruker, Karlsruhe, Germany) was used to record the ${ }^{1} \mathrm{H}-\mathrm{NMR}$ and ${ }^{13} \mathrm{C}-\mathrm{NMR}$ using $\mathrm{CDCl}_{3}$ or $\mathrm{D}_{2} \mathrm{O}$ as solvents and TMS as the internal standard.

\subsection{Synthesis of Mono-6-O-p-toluenesulfonyl- $\beta$-cyclodextrin (tosyl- $\beta-C D$ )}

The synthesis of mono-6-O-p-toluenesulfonyl- $\beta$-cyclodextrin was carried out using a previously reported procedure [38]. In a $500 \mathrm{~mL}$ three-necked round-bottom flask, $\beta$-CD (5.0 g, $4.4 \mathrm{mmol})$ was melted in $125 \mathrm{~mL}$ of water at $60^{\circ} \mathrm{C}$ under vigorous stirring. After cooling to room temperature, finely powdered tosylimidazole ( $3 \mathrm{~g}, 13.5 \mathrm{mmol}$ ) was added to the suspension. After $6 \mathrm{~h}$, sodium hydroxide $(2.25 \mathrm{~g}, 56.25 \mathrm{mmol})$ in $6.52 \mathrm{~mL}$ of water was added gradually over $20 \mathrm{~min}$. After $10 \mathrm{~min}$, the unreacted 1 tosylimidazole was separated by filtration. To quench the reaction, ammonium chloride $(6.03 \mathrm{~g}$, $112.5 \mathrm{mmol}$ ) was then added to the mixture. The resulting solution was concentrated by blowing air onto its surface overnight, precipitating the product from the solution. The reaction mass was filtered, and the obtained solid was washed twice with ice water and acetone. Afterwards, high vacuum-dried tosyl $\beta$-CD was obtained in a $14.1 \%$ yield.

\subsection{Synthesis of Mono-6-deoxy-6-aminoethylamino- $\beta$-cyclodextrin (Et- $\beta$-CD) [39]}

Tosyl $\beta-C D(3 \mathrm{~g}, 2.33 \mathrm{mmol})$ was dissolved in ethylenediamine $(10 \mathrm{~mL})$ under $\mathrm{N}_{2}$. The mixtures were stirred at $60{ }^{\circ} \mathrm{C}$ for $12 \mathrm{~h}$ and the cooled to room temperature. After cooling, the sample was precipitated by adding a large amount of acetone. This was done three times. The precipitated crude product was purified by flash column chromatography using 70:20:10 $\left(\mathrm{MeOH}: \mathrm{H}_{2} \mathrm{O}: \mathrm{NH}_{4} \mathrm{OH}\right)$ as an eluent. The yield was $790 \mathrm{mg}(57.66 \%)$.

\subsection{Synthesis of PdLn@Et- $\beta-C D$ Catalyst}

The Et $-\beta-C D(0.351 \mathrm{~g}, 0.3 \mathrm{mM})$ and $\mathrm{Pd}(\mathrm{OAc})_{2}(0.0225 \mathrm{~g}, 0.1 \mathrm{mM})$ were dissolved in anhydrous toluene $(18.0 \mathrm{~mL})$. The resulting reaction mixture was stirred at room temperature for $12 \mathrm{~h}$. Then, the resulting precipitate was filtered and washed with acetone to remove free palladium and dried in vacuum at $55^{\circ} \mathrm{C}$. A light yellow colored PdLn@Et- $\beta$-CD powder was obtained.

\subsection{General Procedure for the Suzuki-Miyaura Coupling Reactions}

Aryl halides (1.0 mmol), arylboronic acid (1.2 mmol), $\mathrm{K}_{2} \mathrm{CO}_{3}(1.5 \mathrm{mmol})$, PdLn@Et- $\beta$-CD $(2 \mathrm{~mol} \%)$, and $4 \mathrm{~mL} \mathrm{H}_{2} \mathrm{O}$ were put into a reaction flask and stirred at $60{ }^{\circ} \mathrm{C}$ under air. After the reaction was complete, the solution was cooled to room temperature. The mixture was then extracted with ethyl acetate, dried $\left(\mathrm{Na}_{2} \mathrm{SO}_{4}\right)$, filtered, and concentrated in vacuo. The crude product was purified by column chromatography on silica gel using hexane/ethyl acetate at 94:06 to afford pure product.

\section{Conclusions}

In conclusion, we designed and synthesized a water-soluble Pd(II) complex of ethylene diamino modified $\beta$-cyclodextrin (PdLn@Et- $\beta$-CD). This PdLn@Et- $\beta$-CD catalyst was clearly characterized by NMR, FT-IR, XRD, and DSC. Moreover, this catalyst was successfully used in Suzuki-Miyaura 
cross-coupling reactions as an environmentally benign, efficient, and reusable homogeneous catalyst, under mild reaction conditions. It can be recovered and reused without the loss of its catalytic activity. Moreover, a molecular complexation study confirmed that the recognition capacity by inclusion complexation of the catalyst clearly contributed to the significant improvement in the conversions of the tried substrates, which was proven by different spectroscopic analysis, such as FT-IR, FE-SEM, 2D NMR (ROESY) spectroscopy, and DSC.

Supplementary Materials: The following are available online at http:/ /www.mdpi.com/2073-4344/9/2/111/s1, Figure S1: MALDI-TOF-MS of Et- $\beta-C D$, Figure S2: ${ }^{1} \mathrm{H}$ NMR of Et- $\beta-C D$ measured in $\mathrm{D}_{2} \mathrm{O}$.

Author Contributions: V.V.S., D.J. and S.J. conceived and wrote the paper.

Funding: This study was supported by the KU Brain Pool Program of Konkuk University and the Bio \& Medical Technology Development Program of the NRF, funded by the Korean government, MSIP (2015M3A9B8031831). This research was also partially supported by Basic Science Research Program through the National Research Foundation of Korea (NRF) funded by the Ministry of Education (NRF-2018R1D1A1B07050830), SDG.

Conflicts of Interest: The authors declare no conflict of interest.

\section{References}

1. Molnár, A.R.D. Efficient, selective, and recyclable palladium catalysts in carbon-carbon coupling reactions. Chem. Rev. 2011, 111, 2251-2320. [CrossRef] [PubMed]

2. Glasspoole, B.W.; Crudden, C.M. Cross-coupling: The final frontier. Nat. Chem. 2011, 3, 912-913. [CrossRef] [PubMed]

3. Fihri, A.; Bouhrara, M.; Nekoueishahraki, B.; Basset, J.-M.; Polshettiwar, V. Nanocatalysts for Suzuki cross-coupling reactions. Chem. Soc. Rev. 2011, 40, 5181-5203. [CrossRef] [PubMed]

4. Saito, N.; Taniguchi, T.; Hoshiya, N.; Shuto, S.; Arisawa, M.; Sato, Y. Double carbonylation of aryl iodides with amines under an atmospheric pressure of carbon monoxide using sulfur-modified Au-supported palladium. Green Chem. 2015, 17, 2358-2361. [CrossRef]

5. Dodson, J.R.; Hunt, A.J.; Parker, H.L.; Yang, Y.; Clark, J.H. Elemental sustainability: Towards the total recovery of scarce metals. Chem. Eng. Process. 2012, 51, 69-78. [CrossRef]

6. Lamblin, M.; Nassar-Hardy, L.; Hierso, J.C.; Fouquet, E.; Felpin, F.X. Recyclable Heterogeneous Palladium Catalysts in Pure Water: Sustainable Developments in Suzuki, Heck, Sonogashira and Tsuji-Trost Reactions. Adv. Synth. Catal. 2010, 352, 33-79. [CrossRef]

7. Lee, D.H.; Kim, J.H.; Jun, B.H.; Kang, H.; Park, J.Y.; Lee, S. Macroporous polystyrene-supported palladium catalyst containing a bulky N-heterocyclic carbene ligand for Suzuki reaction of aryl chlorides. Org. Lett. 2008, 10, 1609-1612. [CrossRef] [PubMed]

8. Sharma, P.; Singh, A.P. Phosphine free SBA-15-EDTA-Pd highly active recyclable catalyst: Synthesis characterization and application for Suzuki and Sonogashira reaction. Catal. Sci. Technol. 2014, 4, 2978-2989. [CrossRef]

9. Taylor, R.H.; Felpin, F.X. Suzuki-Miyaura Reactions of Arenediazonium Salts Catalyzed by Pd(0)/C. One-Pot Chemoselective Double Cross-Coupling Reactions. Org. Lett. 2007, 9, 2911-2914. [CrossRef] [PubMed]

10. Elazab, H.A.; Siamaki, A.R.; Moussa, S.; Gupton, B.F.; El-Shall, M.S. Highly efficient and magnetically recyclable graphene-supported $\mathrm{Pd} / \mathrm{Fe}_{3} \mathrm{O}_{4}$ nanoparticle catalysts for Suzuki and Heck cross-coupling reactions. Appl. Catal. A Gener. 2015, 491, 58-69. [CrossRef]

11. Zhang, Q.; Su, H.; Luo, J.; Wei, Y.Y. "Click" magnetic nanoparticle-supported palladium catalyst: A phosphine-free, highly efficient and magnetically recoverable catalyst for Suzuki-Miyaura coupling reactions. Catal. Sci. Technol. 2013, 3, 235-243. [CrossRef]

12. Karimi, B.; Mansouri, F.; Vali, H. A highly water-dispersible/magnetically separable palladium catalyst based on a $\mathrm{Fe}_{3} \mathrm{O}_{4} @ \mathrm{SiO}_{2}$ anchored TEG-imidazolium ionic liquid for the Suzuki-Miyaura coupling reaction in water. Green Chem. 2014, 16, 2587-2596. [CrossRef]

13. Höppener, S.; Schubert, U.S.; Ignaszak, A. Electrodeposited palladium on MWCNTs as 'semi-soluble heterogeneous' catalyst for cross-coupling reactions. Tetrahedron Lett. 2015, 56, 4084-4087. 
14. Bortolotto, T.; Facchinetto, S.E.; Trindade, S.G.; Ossig, A.; Petzhold, C.L.; Vargas, J.; Rodrigues, O.E.D.; Giacomelli, C.; Schmidt, V. Polymer-coated palladium nanoparticle catalysts for Suzuki coupling reactions. J. Colloid Interface Sci. 2015, 439, 154-161. [CrossRef] [PubMed]

15. Sharma, R.K.; Sharma, S.; Dutta, S.; Zborilb, R.; Gawande, M.B. Silica-nanosphere-based organic-inorganic hybrid nanomaterials: Synthesis, functionalization and applications in catalysis. Green Chem. 2015, 17, 3207-3230. [CrossRef]

16. Ogasawara, S.; Kato, S. Palladium Nanoparticles Captured in Microporous Polymers: A Tailor-Made Catalyst for Heterogeneous Carbon Cross-Coupling Reactions. J. Am. Chem. Soc. 2010, 132, 4608-4613. [CrossRef] [PubMed]

17. Duan, L.; Fu, R.; Xiao, Z.; Zhao, Q.; Wang, J.Q.; Chen, S.; Wan, Y. Activation of Aryl Chlorides in Water under Phase-Transfer Agent-Free and Ligand-Free Suzuki Coupling by Heterogeneous Palladium Supported on Hybrid Mesoporous Carbon. ACS Catal. 2015, 5, 575-586. [CrossRef]

18. Gómez-Martínez, M.; Buxaderas, E.; Pastor, I.M.; Alonso, D.A. Palladium nanoparticles supported on graphene and reduced graphene oxide as efficient recyclable catalyst for the Suzuki-Miyaura reaction of potassium aryltrifluoroborates. J. Mol. Catal. A 2015, 404-405, 1-7. [CrossRef]

19. Putta, C.; Sharavath, V.; Sarkara, S.; Ghosh, S. Palladium nanoparticles on b-cyclodextrin functionalised graphene nanosheets: A supramolecular based heterogeneous catalyst for $\mathrm{C}-\mathrm{C}$ coupling reactions under green reaction conditions. RSC Adv. 2015, 5, 6652-6660. [CrossRef]

20. Qi, M.; Tan, P.Z.; Xue, F.; Malhi, H.S.; Zhang, Z.X.; Young, D.J.; Andy Hor, T.S. A supramolecular recyclable catalyst for aqueous Suzuki-Miyaura coupling. RSC Adv. 2015, 5, 3590-3596. [CrossRef]

21. Guitet, M.; Marcelo, F.; Beaumais, S.A.; Zhang, Y.; Jiménez-Barbero, J.; Tilloy, S.; Monflier, E.; Ménand, M.; Sollogoub, M. Diametrically Opposed Carbenes on an $\alpha$-Cyclodextrin: Synthesis, Characterization of Organometallic Complexes and Suzuki-Miyaura Couplingin Ethanol and in Water. Eur. J. Org. Chem. 2013, 3691-3696. [CrossRef]

22. Cassez, A.; Ponchel, A.; Hapiot, F.; Monflier, E. Unexpected Multifunctional Effects of Methylated Cyclodextrins in a Palladium Charcoal-Catalyzed Suzuki-Miyaura Reaction. Org. Lett. 2006, 8, 4823-4826. [CrossRef] [PubMed]

23. Guo, Y.; Li, J.; Shi, X.; Liu, Y.; Xie, K.; Liu, Y.; Jiang, Y.; Yang, B.; Yang, R. Cyclodextrin-supported palladium complex: A highly active and recoverable catalyst for Suzuki-Miyaura cross-coupling reaction in aqueous medium. Appl. Organometal. Chem. 2017, 31, e3592. [CrossRef]

24. Legrand, F.; Ménand, M.; Sollogoub, M.; Tilloy, S.; Monflier, E. An N-heterocyclic carbene ligand based on a $\beta$-cyclodextrin-imidazolium salt: Synthesis, characterization of organometallic complexes and Suzuki coupling. New J. Chem. 2011, 35, 2061-2065. [CrossRef]

25. Yang, R.; Chen, J.B.; Xiao, C.F.; Liu, Z.C.; Gao, Z.Y.; Yan, S.J.; Zhang, J.H.; Zhang, H.B.; Lin, J. Inclusion complex of GA-13316 with -cyclodextrin: Preparation, characterization, molecular modeling, and in vitro evaluation. Carbohydr. Polym. 2014, 111, 655-662. [CrossRef]

26. Wang, F.; Yang, B.; Zhao, Y.L.; Liao, X.L.; Gao, C.Z.; Jiang, R.J.; Han, B.; Yang, J.; Liu, M.; Zhou, R.G. Host-guest inclusion system of scutellarein with 2-hydroxypropyl-beta-cyclodextrin: Preparation, characterization, and anticancer activity. J. Biomater. Sci. Polym. E 2014, 6, 594-607. [CrossRef] [PubMed]

27. Thombal, R.S.; Jadhav, V.H. Biomass derived-cyclodextrin- $\mathrm{SO}_{3} \mathrm{H}$ carbonaceous solid acid catalyst for catalytic conversion of carbohydrates to 5-hydroxymethylfurfural. Appl. Catal. A 2015, 499, 213-216. [CrossRef]

28. Khana, R.I.; Pitchumani, K. A pyridinium modified $\beta$-cyclodextrin: An ionic supramolecular ligand for palladium acetate in C-C coupling reactions in water. Green Chem. 2016, 18, 5518-5528. [CrossRef]

29. Dindulkar, S.D.; Jeong, D.; Kim, H.; Jung, S. Functionalized $\beta$-cyclodextrin as supramolecular ligand and their $\mathrm{Pd}(\mathrm{OAc})_{2}$ complex: Highly efficient and reusable catalyst for Mizoroki-Heck cross-coupling reactions in aqueous medium. Carbohydr. Res. 2016, 430, 85-94. [CrossRef]

30. Bellia, F.; La Mendola, D.; Pedone, C.; Rizzarelli, E.; Saviano, M.; Vecchio, G. Selectively functionalized cyclodextrins and their metal complexes. Chem. Soc. Rev. 2009, 38, 2756-2781. [CrossRef]

31. Hapiot, F.; Ponchel, A.; Tilloy, S.; Monflier, E. Cyclodextrins and their applications in aqueous-phase metal-catalyzed reactions. C. R. Chim. 2011, 14, 149-166. [CrossRef]

32. Xue, C.; Palaniappan, K.; Arumugam, G.; Hackney, S.A.; Liu, J.; Liu, H. Sonogashira reactions catalyzed by water-soluble, b-cyclodextrin-capped palladium nanoparticles. Catal. Lett. 2007, 116, 94-100. [CrossRef] 
33. Saha, S.; Roy, A.; Roy, K.; Roy, M.N. Study to explore the mechanism to form inclusion complexes of $\beta$-cyclodextrin with vitamin molecules. Sci. Rep. 2016, 6, 35764. [CrossRef]

34. Patel, R.; Patel, M. Solid-state characterization and in vitro dissolution behavior of lorazepam: Hydroxypropyl- $\beta$-cyclodextrin inclusion complex. Drug Discov. Ther. 2010, 4, 442-452.

35. de Araujo, D.R.; Tsuneda, S.S.; Cereda, C.M.; Carvalho, F.D.G.; Preté, P.S.; Fernandes, S.A.; Yokaichiya, F.; Franco, M.K.; Mazzaro, I.; Fraceto, L.F.; et al. Development and pharmacological evaluation of ropivacaine-2-hydroxypropyl-beta-cyclodextrin inclusion complex. Eur. J. Pharm. Sci. 2008, 33, 60-71. [CrossRef]

36. Kamphorst, A.O.; de Sá, I.M.; Faria, A.M.C.; Sinisterra, R.D. Association complexes between ovalbumin and cyclodextrins have no effect on the immunological properties of ovalbumin. Eur. J. Pharm. Biopharm. 2004, 57, 199-205. [CrossRef]

37. Schmidt, A.F.; Kurokhtina, A.A. Distinguishing between the homogeneous and heterogeneous mechanisms of catalysis in the Mizoroki-Heck and Suzuki-Miyaura reactions: Problems and prospects. Kinet. Catal. 2012, 53, 714-730. [CrossRef]

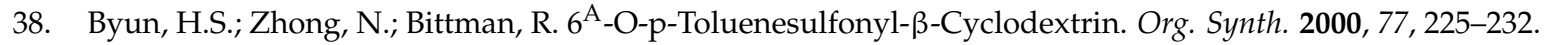

39. Bonomo, R.P.; Cucinotta, V.; Allessandro, F.D.; Impellizzeri, G.; Maccarrone, G.; Rizzarelli, E.; Vecchio, G. Coordination properties of 6-deoxy-6-[1-(2-amino) ethylamino]- $\beta$-cyclodextrin and the ability of itscopper(II) complex to recognize and separate amino acid enantiomeric pairs. J. Incl. Phenom. Mol. Recognit. Chem. 1993, 15, 167-180. [CrossRef]

(C) 2019 by the authors. Licensee MDPI, Basel, Switzerland. This article is an open access article distributed under the terms and conditions of the Creative Commons Attribution (CC BY) license (http:/ / creativecommons.org/licenses/by/4.0/). 